\title{
Short-Term Therapy with Rosiglitazone, a PPAR- $y$ Agonist, Improves Metabolic Profile and Vascular Function in Nonobese Lean Wistar Rats
}

\author{
Mohammad M. Naderali, ${ }^{1}$ Imose Itua, ${ }^{2}$ Abdul-Razak Abubakari, ${ }^{2}$ and Ebrahim K. Naderali ${ }^{2}$ \\ ${ }^{1}$ Calderstones School, Harthill Road, Liverpool L18 3HS, UK \\ ${ }^{2}$ Department of Health Sciences, Liverpool Hope University, Hope Park, Liverpool L16 9JD, UK
}

Correspondence should be addressed to Ebrahim K. Naderali, naderae@hope.ac.uk

Received 19 May 2012; Accepted 21 June 2012

Academic Editors: H. Cerecetto, K. Lutfy, and F. G. M. Russel

Copyright (c) 2012 Mohammad M. Naderali et al. This is an open access article distributed under the Creative Commons Attribution License, which permits unrestricted use, distribution, and reproduction in any medium, provided the original work is properly cited.

\begin{abstract}
A number of preclinical and clinical studies have reported blood-pressure-lowering benefits of thiazolidinediones in diabetic subjects and animal models of diabetes. This study was designed to further elucidate vascular effects of rosiglitazone, on healthy nonobese, lean animals. Adult male Wistar rats were randomized and assigned to control and rosiglitazone-treated groups and were dosed daily with either vehicle or rosiglitazone $\left(10 \mathrm{mg} \mathrm{kg}^{-1} \mathrm{day}^{-1}\right)$ by oral gavage for 5 days. Compared with control group, rosiglitazone treatment significantly reduced plasma levels of triglycerides $(>240 \%)$ and nonesterified free fatty acids $(>268 \%)$ (both, $P<0.001$ ). There were no changes in vascular contractility to $\mathrm{KCl}$ or noradrenaline between two groups. However, rosiglitazone therapy improved carbamylcholine-induced vasorelaxation $(93 \pm 3 \%$ versus control $78 \pm 2, P<0.01)$ an effect which was abolished by L-NAME. There was no difference in sodium nitroprusside-induced vasorelaxation between the control and rosiglitazone-treated animals. These results indicate that short-term rosiglitazone therapy improves both metabolic profile and vascular function in lean rats. The vascular effect of rosiglitazone appears to be mediated by alteration in NO production possibly by activation of endothelial PPAR $\gamma$. This increased NO production together with improved lipid profile may explain mechanism(s) of blood-pressure-lowering effects of thiazolidinediones on both human and experimental animals.
\end{abstract}

\section{Introduction}

Metabolic syndrome (syndrome X), known as a cluster of insulin resistance, abnormal glucose tolerance, abdominal obesity, dyslipidaemia, and arterial disease [1], is associated with substantially increased risk of cardiovascular disease resulting in increased morbidity and premature mortality. Insulin resistance is thought to be the primary abnormality in syndrome X. The increased cardiovascular disorders seen in syndrome $\mathrm{X}$ are thought to be consequences of at least (a) alterations in direct effects of insulin on vascular smooth muscle proliferation [2], (b) indirect effects via activation of the sympathetic nervous system [3], and (c) resistance to vasodilator effects of insulin [4].

The role of endothelium in the regulation of vascular tone by producing various vasoactive mediators which include nitric oxide (NO) and endothelin, both of which acting on the underlying vascular smooth muscle to modulate arterial contractility, is well understood. Impaired endothelium-dependent vasorelaxation has been demonstrated in obesity, type 2 diabetes, and hypertension [57] with the most striking abnormality being attenuation of acetylcholine-induced NO-dependent vasodilatation.

Thiazolidinediones (TZDs), such as pioglitazone and rosiglitazone, are effective in the management of type 2 diabetes mellitus. They bind to the nuclear peroxisome proliferator-activated receptor- $\gamma$ (PPAR- $\gamma$ ), and consequential improvements in insulin resistance and glucose metabolism are principally attributed to decreased free fatty acid concentrations $[8,9]$. They improve metabolic abnormalities in animal models of insulin resistance and type 2 diabetes $[5,10]$ and in human subjects with type 
2 diabetes mellitus [11, 12]. A variety of studies have suggested that thiazolidinediones may also have independent beneficial effects on the vasculature. These included lowering of blood pressure in fatty Zucker rats [13], genetically obese diabetic rats [14], diet-induced hypertensive rats [15], and, Dahl salt-sensitive rats [16]. Moreover, TZDs have been reported to reduce vascular adverse remodeling, and preserve intramyocardial vascularization in renovascular hypertensive rats (2K1C model) [17] as well as direct vasorelaxant effect and endothelial protective effects on arteries from obese Zucker rats $[18,19]$. Similar studies in human subjects with type 2 diabetes mellitus have reported endothelial function improvement $[20,21]$. Therefore, it appears that TZDs have a significantly positive effects on vascular function.

On examination of the effects of the TZD on metabolic and/or cardiovascular function, a vast majority of the animal or human studies are performed on well-established disease status. Thus, it is not possible to extrapolate if an early intervention by TZD's would also have a significant effect on cardiovascular function in prediabetic status. Hence, this study was designed to evaluate vascular effects of acute (5 day) administration of rosiglitazone in chowfed male Wistar rats. In this study, resistance arteries were deployed to measure vascular function, as these vessels represent endothelial function throughout the vasculature and are believed to be involved in determining the increase in peripheral resistance that leads to the development of hypertension [22].

\section{Material and Methods}

2.1. Animals. Adult (12-week-old) male Wistar rats $(n=20)$ were randomized and assigned to a control group $(n=$ $10,300.2 \pm 5.4 \mathrm{~g})$ and a rosiglitazone-treated group ( $n=$ $10,302.5 \pm 4.9 \mathrm{~g}$ ). All animals had free access to standard laboratory pelleted diet (CRM Biosure, Cambridge, UK) and water. They were housed in pairs under controlled environmental conditions $\left(19-22^{\circ} \mathrm{C} ; 30-40 \%\right.$ humidity) and a 12-hour light/dark cycle (lights on at 08:00 h). All animals were dosed at 08:00 daily for 5 days with either vehicle ( $1 \%$ carboxymethyl cellulose at $3 \mathrm{~mL} \mathrm{~kg}^{-1}$ body weight) or rosiglitazone $\left(10 \mathrm{mg} \mathrm{kg}^{-1} \mathrm{day}^{-1}\right)$ by oral gavage.

The rats were killed 2 hours after last dose by $\mathrm{CO}_{2}$ inhalation. Blood was removed by cardiac puncture into cold heparinized tubes and hematocrit levels were measured. The gonadal and perirenal fat pads and the gastrocnemius muscle were dissected and weighed. Plasma was immediately separated by centrifugation before being frozen for later measurements of nonesterified free fatty acids (NEFA) and triglycerides (TG), using commercially available diagnostic kits (Roche \& Sigma Diagnostics, resp.).

2.2. Assessment of Vascular Function. Four third-order mesenteric arteries ( $<250 \mu \mathrm{m}$ diameter, $2 \mathrm{~mm}$ lengths) were carefully dissected from each animal. Each artery was freed of fat and connective tissue and mounted on two $40 \mu \mathrm{m}$ diameter stainless-steel wires in an automated myograph (Cambustion, Cambridge, UK), based on the principle of the Mulvany myograph. The vessels (in duplicate) were incubated in a $5 \mathrm{~mL}$ organ bath containing physiological salt solution (PSS; composition [in $\mathrm{mM}$ ]: $\mathrm{NaCl} \mathrm{119,} \mathrm{KCl} 4.7$, $\mathrm{CaCl}_{2} 2.5, \mathrm{MgSO}_{4}$ 1.17, $\mathrm{NaHCO}_{3} 25, \mathrm{KH}_{2} \mathrm{PO}_{4} 1.18$, EDTA 0.026 and glucose 5.5) gassed with $95 \% \mathrm{O}_{2}$ and $5 \% \mathrm{CO}_{2}$ at $37^{\circ} \mathrm{C}$.

After 30 min equilibration, the length-tension characteristics for each vessel were determined as described previously [23]. The computer also calculated the target tension that each vessel should develop in response to a maximal stimulus. Arteries were then allowed a further $30 \mathrm{~min}$ to equilibrate before being depolarized twice with high-potassium physiological salt solution (KPSS, $125 \mathrm{mM}$ ), in which $\mathrm{NaCl}$ in normal PSS was replaced by an equimolar concentration of $\mathrm{KCl}$. Any vessel failing to reach its predetermined target tension in response to vasoconstriction with $\mathrm{KCl}(125 \mathrm{mM})$ was discarded. Cumulative concentration-response curves to either $\mathrm{KCl}(10-125 \mathrm{mM})$ or noradrenaline (NA, 0.5-6 $\mu \mathrm{M}$ ) were then carried out.

\subsection{Assessment of Endothelium-Dependent and-Independent Vascular Relaxation. Changes in endothelial-dependent and -independent vascular functions were assessed by observ- ing any alterations invascular reactivity to carbamyl- choline (CCh), and sodium nirtoprusside (SNP) in NA- preconstricted arteries. Arteries were contracted with a supramaximal concentration of NA $(8 \mu \mathrm{M})$. When con- traction reached a plateau after 2 minutes, concentration- response curves were carried out to either CCh or SNP (for both, $10 \mathrm{nM}-100 \mu \mathrm{M}$ ). Vascular responses to CCh were measured in absence or presence of L-NAME $(100 \mu \mathrm{M})$.}

2.4. Reagents. Noradrenaline, carbamylcholine, sodium nitroprusside (SNP), N(G)-nitro-L-arginine methyl ester (L-NAME), rosiglitazone, and carboxymethyl cellulose were all obtained from Sigma Chemicals (UK). Noradrenaline, CCh, SNP, and L-NAME were all dissolved in double distilled water. Both noradrenaline and SNP were kept away from light throughout the experiment. All water-soluble solutions were freshly made on the day of the experiment.

2.5. Data Interpretation and Statistical Analyses. Vasoconstriction in response to $\mathrm{NA}$ and $\mathrm{KCl}$ were expressed as absolute force generated. Vasorelaxation responses to $\mathrm{CCh}$ and SNP were calculated as the percentage reduction from the maximal tension generated in response to the supramaximal concentration of NA $(8 \mu \mathrm{M})$. Data are expressed as mean \pm S.E.M. Statistical significance was tested using repeatedmeasures ANOVA or the Mann-Whitney test, as appropriate. Results were considered statistically significant at the $P<0.05$ levels.

\section{Results}

3.1. Body Weight and Metabolic Data. There were no significant differences in body weight $(P=0.399)$, and perirenal fat pad mass $(P=0.239)$, and gastrocnemius muscle mass $(P=0.659)$ between two experimental groups (Table 1$)$. 
TABle 1: Physiological and metabolic characteristics of the 2 experimental groups. Data are mean \pm SEM.

\begin{tabular}{lcc}
\hline & $\begin{array}{c}\text { Controls } \\
(n=10)\end{array}$ & $\begin{array}{c}\text { Rosiglitazone } \\
(n=10)\end{array}$ \\
\hline Body weight (g) & & \\
$\quad$ (i) Initial & $300.2 \pm 5.4$ & $302.7 \pm 4.9$ \\
$\quad$ (ii) Final & $325.5 \pm 5.6$ & $339.9 \pm 8.7$ \\
Gonadal fat-pad mass (g) & $1.13 \pm 0.06$ & $1.47 \pm 0.09^{\mathrm{a}}$ \\
Perirenal fat-pad mass (g) & $1.12 \pm 0.08$ & $1.31 \pm 0.12$ \\
Gastrocnemius muscle mass (g) & $1.86 \pm 0.05$ & $1.92 \pm 0.06$ \\
Fat/lean ratio* & $1.23 \pm 0.07$ & $1.45 \pm 0.08$ \\
Plasma triglycerides (mM) & $1.34 \pm 0.11$ & $0.50 \pm 0.04^{\mathrm{b}}$ \\
Plasma NEFA (mM) & $0.20 \pm 0.01$ & $0.08 \pm 0.00^{\mathrm{b}}$ \\
Total cholesterol & $2.33 \pm 0.10$ & $2.40 \pm 0.96$ \\
HDL cholesterol & $0.92 \pm 0.08$ & $1.01 \pm 0.08$ \\
LDL cholesterol & $2.12 \pm 0.20$ & $2.66 \pm 0.17$ \\
Hematocrit & $45.9 \pm 0.2$ & $41.8 \pm 0.5^{\mathrm{b}}$ \\
\hline
\end{tabular}

${ }^{*}$ Fat/Lean ratio $=$ sum of white fat pad masses/gastrocnemius muscle mass; ${ }^{\text {a }} P<0.01,{ }^{\text {b }} P<0.001$ versus controls.

However, compared with control groups, rosiglitazonetreated animals, had significantly higher gonadal fat pad mass $(P<0.01)$, and lower hematocrit $(P<0.001)$ (Table 1$)$. The increase in gonadal fat pad mass in turn translated to an increase in fat/lean ratio in rosiglitazone-treated animals, compared with their counterpart control group. However, this increase in fat/lean ratio was not statistically significant from that of control group $(P=0.0830)$ (Table 1).

Rosiglitazone significantly lowered plasma levels of triglycerides $(>240 \%)$ and NEFA $(>268 \%)$ (for both, $P<$ 0.001 ) than control animals; however, it had no effects on plasma levels of total cholesterol, LDL, and HDL.

3.2. Vascular Responses. There were no significant differences in arterial diameter between two groups in this study.

3.3. Contractile Responses. There were no significant differences in $\mathrm{KCl}$-induced arterial contraction between the two groups. $\mathrm{KCl}$ concentration-response curves in both groups produced similar maximal contractile generated forces (control: $7.29 \pm 0.50$ versus rosiglitazone-treated: 7.23 $\pm 0.38 \mathrm{mN}$ ). Similar outcome was also seen with NAinduced contractility. NA-induced contractile curves were similar between control and rosiglitazone-treated animals, producing comparable maximal contractions between two groups (control: $13.99 \pm 1.21$ versus rosiglitazone-treated: $13.33 \pm 0.89)$ (Figure 1).

3.4. Endothelium-Dependent Relaxation. Arteries from rosiglitazone-treated rats showed significant $(P<0.001)$ increase in vasorelaxation response to $\mathrm{CCh}$ compared with that of control animals (rosiglitazone-treated: 93 $\pm 3 \%$ versus control $78 \pm 2$ (Figure 2(a)). However, this improved vasorelaxation in arteries from rosiglitazonetreated animals was abolished in the presence of L-NAME (rosiglitazone-treated: $73 \pm 2 \%$ versus control $77 \pm 2$ (Figure 2(b)).

3.5. Endothelium-Independent Relaxation. The shapes of concentration response curves to SNP were almost identical in both groups. Moreover, there were no significant differences in maximum SNP-induced vasorelaxation between the two groups (rosiglitazone-treated: $88 \pm 2 \%$ versus control 91 $\pm 2 \%$ (Figure 3 ).

\section{Discussion}

Rosiglitazone, a thiazolidinedione insulin-sensitizing agent which acts by stimulating PPAR- $\gamma$, has been shown to improve endothelial function in both human and animals $[20,24,25]$. Despite reports of expression and function of PPAR $y$ in rat and human vascular smooth muscle cells [26], studies in human and rodents have failed to show a direct vasorelaxant effect of rosiglitazone [27].

The beneficial vascular effects of rosiglitazone involve vasorelaxation but not vasocontraction mechanism(s). In fact, it is reported that rosiglitazone had no effect on contractile responses to NA, but markedly increased sensitivity to Acetylcholine- (Ach-) induced vasorelaxation [28]. Interestingly similar effects of rosiglitazone were seen in this study, where five-day rosiglitazone treatment did not alter contractile responses to $\mathrm{NA}$ or $\mathrm{KCl}$, while it significantly improved CCh-induced vasorelaxation indicating a role for rosiglitazone in improving endothelial function which may involve upregulation of Akt/eNOS pathways [29].

Although rosiglitazone improved CCh-induced vasorelaxation, it failed to significantly affect SNP-induced vasorelaxation suggesting that rosiglitazone does not influence vasorelaxation via smooth muscle cyclic guanosine monophosphate (cGMP) pathway. Interestingly a recent study reported blunting of rosiglitazone effects in lowering blood pressure and vasorelaxation in animals lacking endothelial but not smooth muscle PPAR (SM22Cre/flox mice) [30], indicating that beneficial effects of rosiglitazone are mediated via activation of specific endothelial PPAR $\gamma$ receptors. Moreover, in streptozotocin- (STZ-) induced diabetic rats rosiglitazone significantly reversed blunting of ACh-induced vasorelaxation [31], further highlighting role of PPAR $\gamma$ agonists in protecting endothelial function. Similar effects have also been described on genetically modified mice where regulation of blood pressure and heart rate under stressed conditions are consequence of activation of endothelial PPAR $y$ receptors [32]. Furthermore, stressinduced (transplantation-induced) endothelial dysfunction is completely restored by rosiglitazone [33] highlighting improvement of endothelial function by activation of PPAR $\gamma$ receptors.

In our study, the increased CCh-induced vasorelaxant effect of rosiglitazone therapy was abolished in the presence of L-NAME. This is in agreement with a previous study 


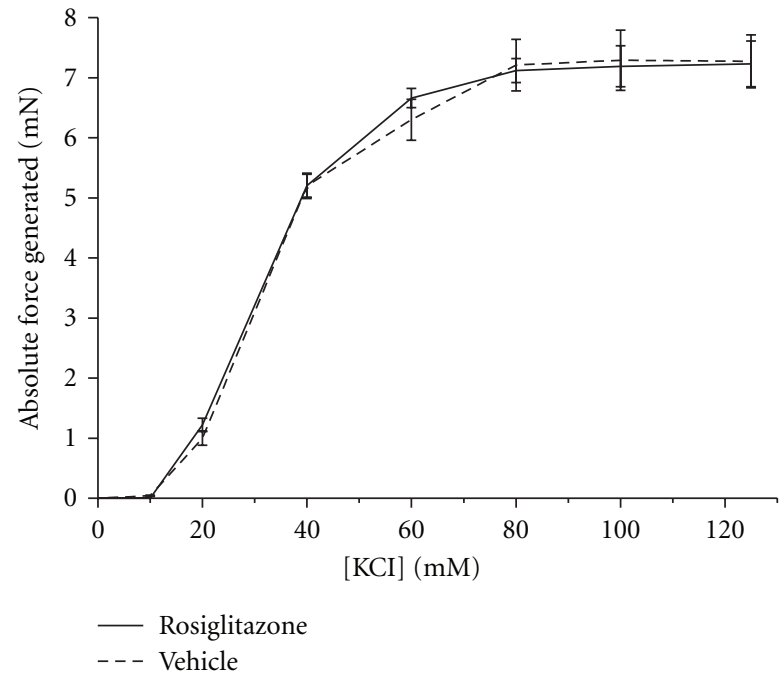

(a)

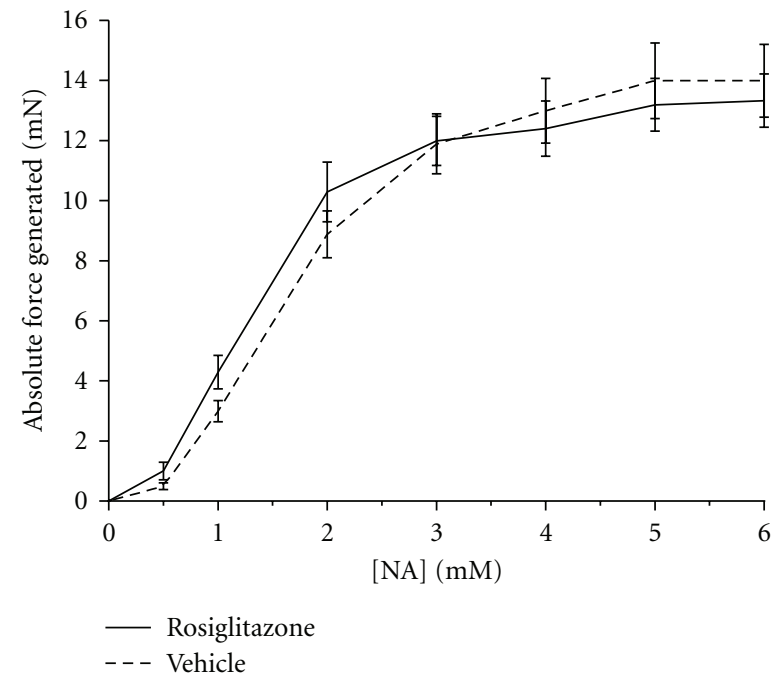

(b)

Figure 1: The effects of (a) $\mathrm{KCl}(10-125 \mathrm{mM})$ and (b) noradrenaline (NA; 0.5-6 $\mu \mathrm{M})$ on arteries from 5-day rosiglitazone-treated and untreated control animals. There were no significant differences between the two groups. Data represent mean \pm S.E.M.

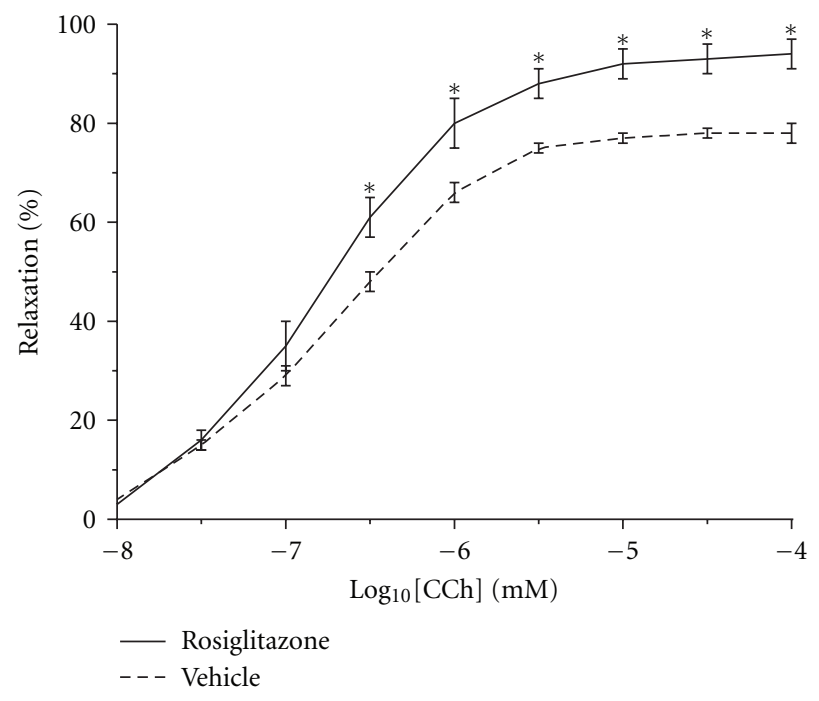

(a)

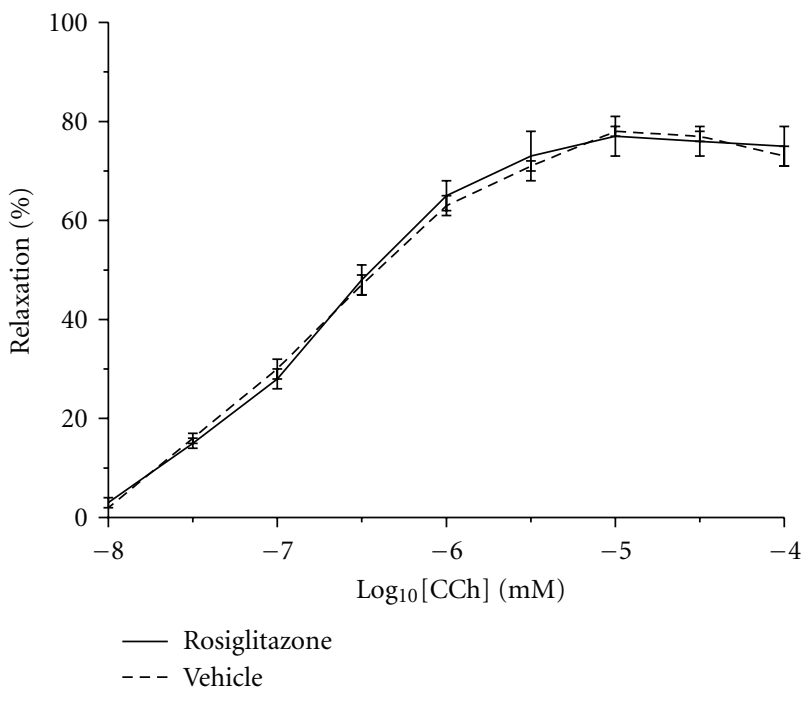

(b)

FIGURE 2: Relaxation curves for carbamylcholine (CCh) on arteries from 5-day rosiglitazone-treated and untreated control animals in (a) absence or (b) presence of L-NAME. Arteries were first precontracted with NA $(8 \mu \mathrm{M})$. When contraction reached a plateau after 2 minutes, concentration-response curves to CCh were carried out in the presence or absence of L-NAME $(100 \mu \mathrm{M})$. Data represent mean \pm S.E.M. The concentration-response curves between untreated controls and rosiglitazone-treated animals differ significantly (by ANOVA, $\left.{ }^{*} P<0.01\right)$ in the absence of L-NAME but not in the presence of L-NAME.

where presence of L-NAME blocked ACh-induced relaxation in pioglitazone-treated STZ-diabetic rats [34]. Taken together, these data suggest that PPAR $\gamma$ activation improves endothelial function, thereby facilitating production and/or release of nitric oxide (NO) vasorelaxant. Although we did not measure NO levels in this study, others have shown an increased basal nitric oxide release in TZD-treated STZdiabetic rats suggesting inhibition of NO breakdown and/or increase of basal and agonist-stimulated production of $\mathrm{NO}$ by pioglitazone [35] and rosiglitazone [36], leading to attenuated endothelial-dependent vasorelaxation.

Rosiglitazone treatment had no effects on total body weight and gastrocnemius muscle mass. Measurements of fat pad masses indicated an increase in gonadal but not in perirenal fat pad mass suggesting selective changes in adiposity in response to rosiglitazone therapy. The importance of this selective increase in fat pad remains to be elucidated. However, in agreement with previous reports 


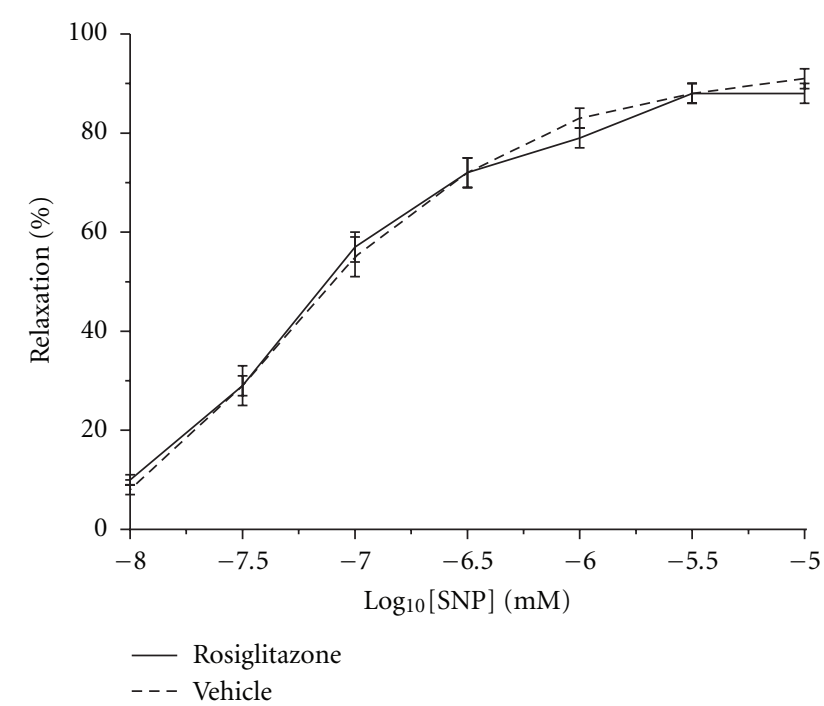

FIGURE 3: Relaxation curves for sodium nitroprusside (SNP) on arteries from 5-day rosiglitazone-treated and untreated control animals. NA $(8 \mu \mathrm{M})$-precontracted arteries were subjected to increasing concentration of SNP. There were no significant differences between the two groups. Data represent mean \pm S.E.

on diabetic animal models, rosiglitazone treatment in this study significantly improved lipid profile of nonobese, lean, nondiabetic animals by reducing plasma levels of NEFA and triglyceride, perhaps by diverting circulating lipids to gonadal fat pad deposition. However, this hypothesis requires further investigation. Rosiglitazone's effects on adipocytes also include increase in adiponectin production [37] which has been shown to have cardioprotective effects [37]. Therefore, it is plausible to suggest that increase in adiponectin together with improved lipid profile may contribute to beneficial effects of rosiglitazone on vascular function.

The potential side effects of thiazolidinediones include oedema and haemodilution at least partially due to an adipose-tissue-selective activation of PKC and vascular permeability [38]. In this study, rosiglitazone treatment significantly reduced red blood cell packed volume (haematocrit). It is possible that lowering haematocrit is a secondary response to rosiglitazone-induced vasodilatation, which in turn activates renin-angiotensin system (RAS) [39] with subsequent haemodilution as a consequence of sodium and water retention. What is important to note is that despite significant beneficial effects of TZD's as an antidiabetic agents, recent reports have highlighted significant increase in cardiac related morbidity and mortality, in particular on development of heart failure in human subjects with type 2 diabetes mellitus [40-42]. However, there are contrasting reports underlining importance of rosiglitazone as a caridoprotective agent in postmyocardial infarction [37]. These conflicting reports suggest existence of multifactorial elements of TZD's effects on cardiovascular function and hence, their use should be tailored for each individual patient in question.
In summary, short-term rosiglitazone therapy improves both metabolic profile and vascular function in lean nondiabetic rats. The beneficial effect of rosiglitazone on vascular reactivity is mediated by activation of endothelial PPAR $\gamma$ receptors leading to increased NO synthesis and production. This increased NO production may, at least in part, explain mechanism(s) of blood-pressure-lowering effects of thiazolidinediones on both human and animals models. Moreover, improved vasorelaxant effect seen by rosiglitazone therapy in this study appears to be a class effect shared with other thiazolidinedione compounds.

\section{Conflict of Interests}

The authors have declared that there is no conflict of interests.

\section{Acknowledgment}

The authors wish to express their gratitude to Miss. Mahdieh Naderali for her editorial assistance in preparing this paper.

\section{References}

[1] G. M. Reaven, "Role of insulin resistance in human disease," Diabetes, vol. 37, no. 12, pp. 1595-1607, 1988.

[2] L. Capron, J. Jarnet, S. Kazandjian, and E. Housset, "Growthpromoting effects of diabetes and insulin on arteries. An in vivo study of rat aorta," Diabetes, vol. 35, no. 9, pp. 973-978, 1986.

[3] E. A. Anderson, T. W. Balon, R. P. Hoffman, and S. A. Sinkey, "Marked hyperinsulinaemia produces both sympathic nueral activation and vasodilataion in normal humans," The Journal of Clinical Investigation, vol. 87, pp. 2246-2252, 1991.

[4] M. Laakso, S. V. Edelman, G. Brechtel, and A. D. Baron, "Impaired insulin-mediated skeletal muscle blood flow in patients with NIDDM," Diabetes, vol. 41, no. 9, pp. 1076-1083, 1992.

[5] E. K. Naderali, M. J. Brown, L. C. Pickavance, J. P. H. Wilding, P. J. Doyle, and G. Williams, "Dietary obesity in the rat induces endothelial dysfunction without causing insulin resistance: a possible role for triacylglycerols," Clinical Science, vol. 101, no. 5, pp. 499-506, 2001.

[6] G. E. McVeigh, G. M. Brennan, G. D. Johnston et al., "Impaired endothelium-dependent and independent vasodilation in patients with type 2 (non-insulin-dependent) diabetes mellitus," Diabetologia, vol. 35, no. 8, pp. 771-776, 1992.

[7] G. F. Watts, S. F. O'Brien, W. Silvester, and J. A. Millar, "Impaired endothelium-dependent and independent dilatation of forearm resistance arteries in men with diet-treated non-insulin-dependent diabetes: role of dyslipidaemia," Clinical Science, vol. 91, no. 5, pp. 567-573, 1996.

[8] A. M. Lefebvre, J. Peinado-Onsurbe, I. Leitersdorf et al., "Regulation of lipoprotein metabolism by thiazolidinediones occurs through a distinct but complementary mechanism relative to fibrates," Arteriosclerosis, Thrombosis, and Vascular Biology, vol. 17, no. 9, pp. 1756-1764, 1997.

[9] Y. Miyazaki, A. Mahankali, M. Matsuda et al., "Improved glycemic control and enhanced insulin sensitivity in type 2 diabetic subjects treated with pioglitazone," Diabetes Care, vol. 24, no. 4, pp. 710-719, 2001. 
[10] L. C. Pickavance, M. Tadayyon, P. S. Widdowson, R. E. Buckingham, and J. P. H. Wilding, "Therapeutic index for rosiglitazone in dietary obese rats: separation of efficacy and haemodilution," British Journal of Pharmacology, vol. 128, no. 7, pp. 1570-1576, 1999.

[11] S. L. Suter, J. J. Nolan, P. Wallace, B. Gumbiner, and J. M. Olefsky, "Metabolic effects of new oral hypoglycemic agent CS-045 in NIDDM subjects," Diabetes Care, vol. 15, no. 2, pp. 193-203, 1992.

[12] S. Kumar, A. J. M. Boulton, H. Beck-Nielsen et al., "Troglitazone, an insulin action enhancer, improves metabolic control in NIDDM patients," Diabetologia, vol. 39, no. 6, pp. 701-709, 1996.

[13] S. Yoshioka, H. Nishino, T. Shiraki et al., "Antihypertensive effects of CS-045 treatment in obese Zucker rats," Metabolism, vol. 42, no. 1, pp. 75-80, 1993.

[14] T. Yoshimoto, M. Naruse, M. Nishikawa et al., "Antihypertensive and vasculo- and renoprotective effects of pioglitazone in genetically obese diabetic rats," American Journal of Physiology, vol. 272, no. 6, pp. E989-E996, 1997.

[15] T. A. Buchanan, W. P. Meehan, Y. Y. Jeng et al., "Blood pressure lowering by pioglitazone. Evidence for a direct vascular effect," The Journal of Clinical Investigation, vol. 96, no. 1, pp. 354-360, 1995.

[16] J. C. Sartori-Valinotti, M. R. Venegas-Pont, B. B. LaMarca et al., "Rosiglitazone reduces blood pressure in female Dahl saltsensitive rats," Steroids, vol. 75, no. 11, pp. 794-799, 2010.

[17] G. de Oliveira Silva-Junior, T. da Silva Torres, L. de Souza Mendonca, and C. Alberto Mandarim-de-Lacerda Carlos, "Rosiglitazone (peroxisome proliferator-activated receptorgamma) counters hypertension and adverse cardiac and vascular remodeling in $2 \mathrm{~K} 1 \mathrm{C}$ hypertensive rats," Experimental and Toxicologic Pathology, vol. 63, no. 1-2, pp. 1-7, 2011.

[18] A. B. Walker, P. D. Chattington, R. E. Buckingham, and G. Williams, "The thiazolidinedione rosiglitazone (BRL-49653) lowers blood pressure and protects against impairment of endothelial function in Zucker fatty rats," Diabetes, vol. 48, no. 7, pp. 1448-1453, 1999.

[19] S. Verma, S. Bhanot, E. Arikawa, L. Yao, and J. H. McNeill, "Direct vasodepressor effects of pioglitazone in spontaneously hypertensive rats," Pharmacology, vol. 56, no. 1, pp. 7-16, 1998.

[20] K. K. Naka, K. Papathanassiou, A. Bechlioulis et al., "Rosiglitazone improves endothelial function in patients with type 2 diabetes treated with insulin," Diabetes and Vascular Disease Research, vol. 8, no. 3, pp. 195-201, 2011.

[21] K. K. Naka, K. Papathanassiou, A. Bechlioulis et al., "Effects of pioglitazone and metformin on vascular endothelial function in patients with type 2 diabetes treated with sulfonylureas," Diabetes and Vascular Disease Research, vol. 9, no. 1, pp. 52$58,2009$.

[22] K. L. Christensen and M. J. Mulvany, "Mesenteric arcade arteries contribute substantially to vascular resistance in conscious rats," Journal of Vascular Research, vol. 30, no. 2, pp. 73-79, 1993.

[23] E. K. Naderali, P. J. Doyle, and G. Williams, "Resveratrol induces vasorelaxation of mesenteric and uterine arteries from female guinea-pigs," Clinical Science, vol. 98, no. 5, pp. 537$543,2000$.

[24] A. S. Kelly, A. M. Thelen, D. R. Kaiser, J. M. Gonzalez-Campoy, and A. J. Bank, "Rosiglitazone improves endothelial function and inflammation but not asymmetric dimethylarginine or oxidative stress inpatients with type 2 diabetes mellitus," Vascular Medicine, vol. 12, no. 4, pp. 311-318, 2007.

[25] J. Tian, W. T. Wong, X. Y. Tian, P. Zhang, Y. Huang, and N. Wang, "Rosiglitazone attenuates endothelin-1-induced vasoconstriction by upregulating endothelial expression of endothelin b receptor," Hypertension, vol. 56, no. 1, pp. 129$135,2010$.

[26] R. E. Law, S. Goetze, X. P. Xi et al., "Expression and function of PPAR $\gamma$ in rat and human vascular smooth muscle cells," Circulation, vol. 101, no. 11, pp. 1311-1318, 2000.

[27] A. B. Walker, E. K. Naderali, P. D. Chattington, R. E. Buckingham, and G. Williams, "Differential vasoactive effects of the insulin sensitizers rosiglitazone (BRL 49653) and troglitazone on human small arteries in vitro," Diabetes, vol. 47, no. 5, pp. 810-814, 1998.

[28] X. Lu, X. Guo, S. K. Karathanasis et al., "Rosiglitazone reverses endothelial dysfunction but not remodeling of femoral artery in Zucker diabetic fatty rats," Cardiovascular Diabetology, vol. 9, article 19, 2010.

[29] C. Liang, Y. Ren, H. Tan et al., "Rosiglitazone via upregulation of Akt/eNOS pathways attenuates dysfunction of endothelial progenitor cells, induced by advanced glycation end products," British Journal of Pharmacology, vol. 158, no. 8, pp. 1865-1873, 2009.

[30] N. Wang, J. D. Symons, H. Zhang, Z. Jia, F. J. Gonzalez, and T. Yang, "Distinct functions of vascular endothelial and smooth muscle PPAR $\gamma$ in regulation of blood pressure and vascular tone," Toxicologic Pathology, vol. 37, no. 1, pp. 21-27, 2009.

[31] S. Wang, J. L. Jiang, C. P. Hu, X. J. Zhang, D. L. Yang, and Y. J. Li, "Relationship between protective effects of rosiglitazone on endothelium and endogenous nitric oxide synthase inhibitor in streptozotocin-induced diabetic rats and cultured endothelial cells," Diabetes/Metabolism Research and Reviews, vol. 23, no. 2, pp. 157-164, 2007.

[32] C. J. Nicol, M. Adachi, T. E. Akiyama, and F. J. Gonzalez, "PPAR $y$ in endothelial cells influences high fat diet-induced hypertension," American Journal of Hypertension, vol. 18, no. 4, pp. 549-556, 2005.

[33] G. Onuta, J. L. Hillebrands, H. Rienstra et al., "Dichotomous effects of rosiglitazone in transplantation-induced systemic vasodilator dysfunction in rats," Transplantation, vol. 85, no. 4, pp. 582-588, 2008.

[34] J. B. Majithiya, A. N. Parmar, C. J. Trivedi, and R. Balaraman, "Effect of pioglitazone on L-NAME induced hypertension in diabetic rats," Vascular Pharmacology, vol. 43, no. 4, pp. 260266, 2005.

[35] J. B. Majithiya, A. N. Paramar, and R. Balaraman, "Pioglitazone, a PPAR $y$ agonist, restores endothelial function in aorta of streptozotocin-induced diabetic rats," Cardiovascular Research, vol. 66, no. 1, pp. 150-161, 2005.

[36] Z. Bagi, A. Koller, and G. Kaley, "PPAR $\gamma$ activation, by reducing oxidative stress, increases NO bioavailability in coronary arterioles of mice with type 2 diabetes," American Journal of Physiology, vol. 286, no. 2, pp. H742-H748, 2004.

[37] L. Tao, Y. Wang, E. Gao et al., "Adiponectin: an indispensable molecule in rosiglitazone cardioprotection following myocardial infarction," Circulation Research, vol. 106, no. 2, pp. 409$417,2010$.

[38] K. B. Sotiropoulos, A. Clermont, Y. Yasuda et al., "Adiposespecific effect of rosiglitazone on vascular permeability and protein kinase $\mathrm{C}$ activation: novel mechanism for PPARgamma agonist's effects on edema and weight gain," The FASEB Journal, vol. 20, no. 8, pp. 1203-1205, 2006. 
[39] L. Ren, N. Liu, H. Zhi et al., "Vasculoprotective effects of rosiglitazone through modulating renin-angiotensin system in vivo and vitro," Cardiovascular Diabetology, vol. 10, no. 1, article 10, 2011.

[40] P. D. Home, S. J. Pocock, H. Beck-Nielsen et al., "Rosiglitazone evaluated for cardiovascular outcomes in oral agent combination therapy for type 2 diabetes (RECORD): a multicentre, randomised, open-label trial," The Lancet, vol. 373, no. 9681, pp. 2125-2135, 2009.

[41] A. V. Hernandez, A. Usmani, A. Rajamanickam, and A. Moheet, "Thiazolidinediones and risk of heart failure in patients with or at high risk of type 2 diabetes mellitus: a metaanalysis and meta-regression analysis of placebo-controlled randomized clinical trials," American Journal of Cardiovascular Drugs, vol. 11, no. 2, pp. 115-128, 2011.

[42] Y. K. Loke, C. S. Kwok, and S. Singh, "Comparative cardiovascular effects of thiazolidinediones: systematic review and meta-analysis of observational studies," British Medical Journal, vol. 342, p. d1309, 2011. 

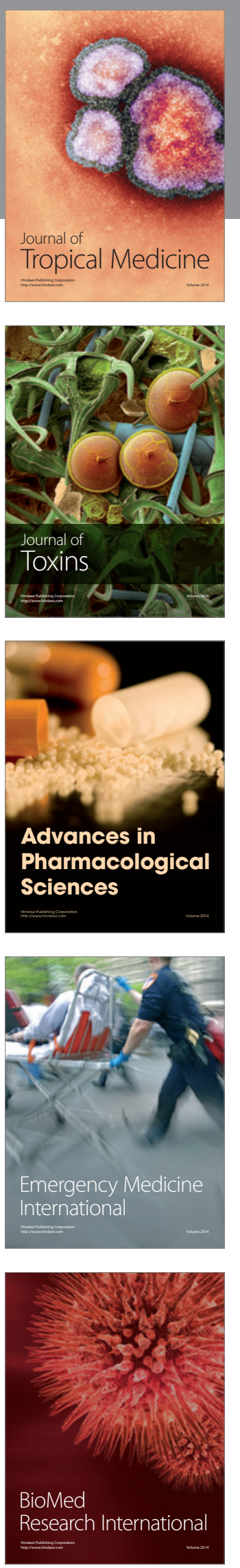
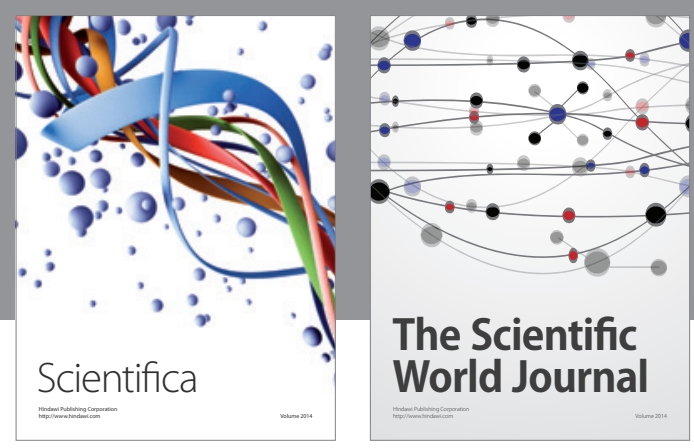

The Scientific World Journal
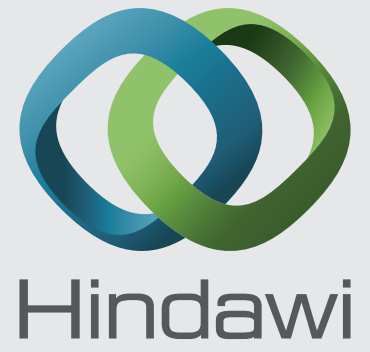

Submit your manuscripts at

http://www.hindawi.com
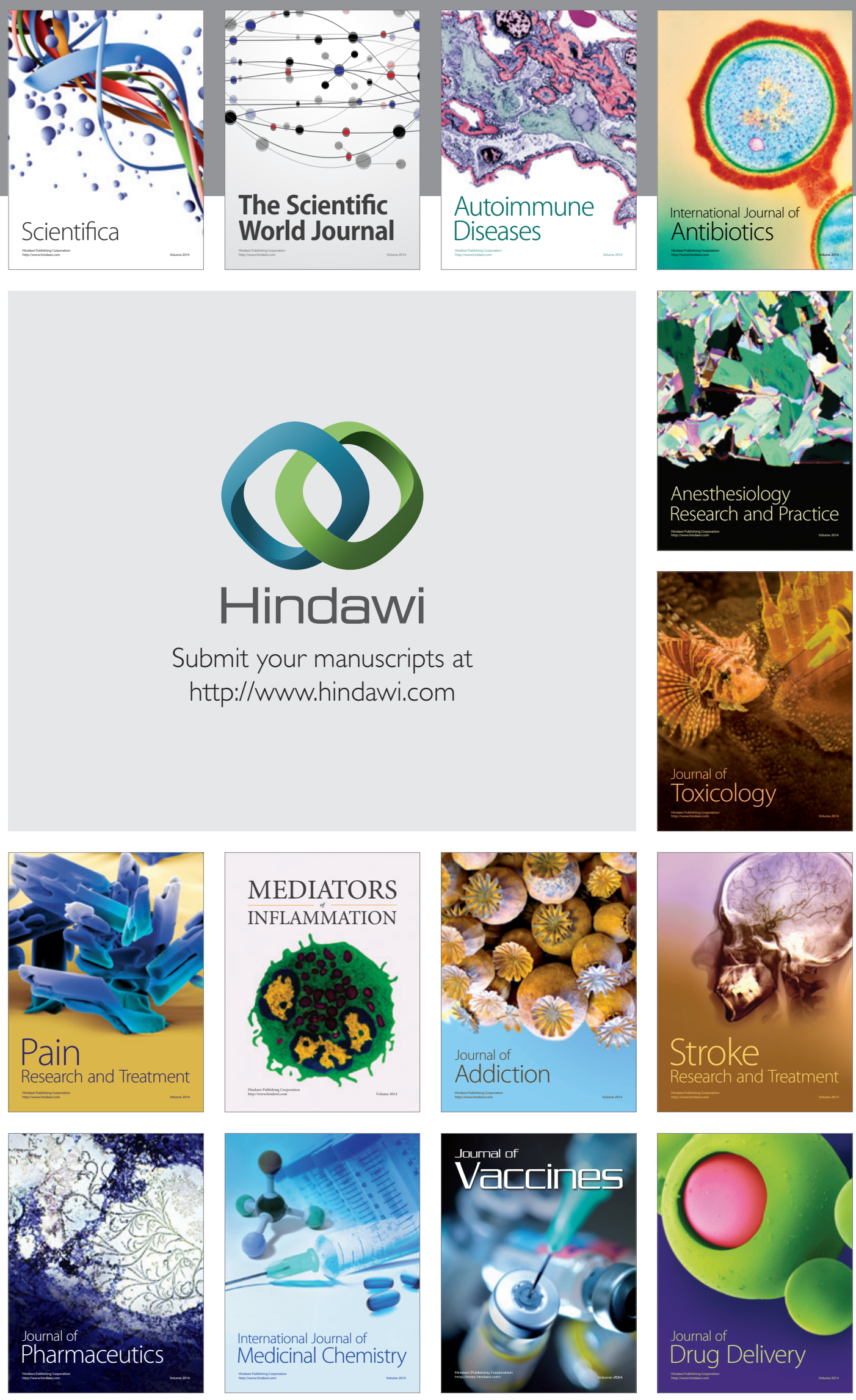